\title{
Business travel decisions and high-speed trains: An ordered logit approach
}

\author{
Federica Rossi ${ }^{1}$, Rico Maggi ${ }^{2}$ \\ ${ }^{1}$ Politecnico di Milano, Milan, Italy \\ ${ }^{2}$ Università della Svizzera italiana, Lugano, Switzerland \\ Received: 25 July 2018/Accepted: 15 November 2019
}

\begin{abstract}
The paper studies the potential impact on business travel of the new highspeed railway line project, called AlpTransit, which will link Lugano, the small economic hub of the southern part of Switzerland, with Zurich, one of the major Swiss economic centres, situated north of the Alps. This infrastructure has enabled travel time between the two cities to decrease considerably from about three hours to less than two hours by the end of 2020.

The question that we pose in this paper is what impact high-speed trains could have, in the short to medium term, on business travel between the two hubs (ex-ante evaluation). Indeed, given the travel time, firms could increase their business-to-business one-day trips, boosting face-to-face interactions within and among enterprises. Our curiosity more specifically regards the potential impact of the change in travel time on the propensity to travel of employees with different functions in various types of firms.

An online survey was conducted among firms located in Ticino, the Swiss Canton that includes Lugano. The data is analysed using four ordered logit models, one for each employee category (CEO, administrative staff, sales personnel, specialists), since hierarchical position and professional status influence business travel characteristics. Results show that internal firm characteristics, such as sector, frequency and destination of current business travels significantly influence the propensity to travel to Zurich more often due to AlpTransit.
\end{abstract}

JEL classification: D22, R40

Key words: High-speed train, business travel, ordered logit, firm behaviour

\section{Introduction}

One of the persistent analytical issues in the economic geography of transport relates to the assessment of the contribution that transport infrastructure makes to the economy.

The majority of the literature analyses transport impact on regional development (Gutiérrez 2001, Marti et al. 2007, Carbo et al. 2019) and companies' relocation strategies (Leitham et al. 2000, Kawamura 2004, De Bok, Sanders 2005), and therefore focuses on long term effects. However, by reducing travel time, a new infrastructure also has various impacts in the short and medium term, in particular on daily choices of firms. 
The paper presents an empirical analysis on firms located in Ticino, the southern Swiss Canton, by studying the influence on one-day business-to-business trips of the new high-speed railway line project, called AlpTransit, which will link Lugano, a small Swiss city in the south, with Zurich, the Swiss economic capital situated north of the Alps. This infrastructure is an ambitious railway project: its first and main segment (Gotthard base tunnel) has been opened in late $2016^{1}$, and the Monte Ceneri base tunnel will complete the North-South link by 2020. Due to the new high-speed railway line, the reduction in travel time will be very significant: from three hours to less than two between the cities of Zurich and Lugano. The Swiss population, and in particular firms' managers, are aware of this project, because of the large advertising campaign that has been conducted.

More precisely, the goals of this work are to investigate if and how high-speed trains could change firms' business relations between a small city (Lugano) and a dominant one (Zurich), which have similar economic structures (they are both specialised in business services, in particular financial services). Second, this work aims to understand if a significant reduction in travel time will have a differentiated influence on some specific firms. Finally, this work will identify the link between firms' characteristics and future business trips within various employee categories.

In order to achieve these goals, the probability that face-to-face contacts will increase after AlpTransit is analysed by distinguishing employee categories: CEO and upper management, administrative staff, sales personnel and specialists. This specification helps identify the probable meeting purpose, for example visiting clients, branches, government departments or attending courses, fairs, conferences and conventions, opening or closing new units, projects, R\&D, etc. (Swarbrooke, Horner 2001, Welch, Worm 2005, Beaverstock et al. 2009). Indeed, strategic decisions "travel" with the CEO and upper management (Jones 2007) and the areas where face-to-face contacts are fundamental for the success of companies are sales and business development (HBR 2009). This specification is also motivated by the fact that not all workers travel: professional status and hierarchical position are significant factors, which influence the business travel characteristics (Aguilera 2008).

While most of the past studies are ex-post evaluations of the impact of an infrastructure, this paper offers an ex-ante evaluation of the AlpTransit project, using individual firm level data. In order to do this, we rely on the stated preference methods, which allow taking into account hypothetical behaviours in the future.

The paper is organised as follows: the next section is dedicated to an overview of the literature, while in the third section the theoretical framework and hypothesis are presented. The following two parts concern the survey and the empirical model. The sixth section highlights the main results and a brief discussion of them. Finally, some conclusions and future research ideas are presented.

\section{Literature review}

Nowadays, doing business means facing the increasing interconnection and globalisation of our world. In this context, business travel (BT) has become a quite common and diffuse practice (Swarbrooke, Horner 2001, Aguilera 2008, UNWTO 2012), and an essential feature of globalised trends like outsourcing, spatial specialisation and multi-plant companies.

Business visits are defined as work-related trips to an irregular place of work, lasting less than 12 months (Aguilera 2008). These kinds of trips have continuously grown in number, despite the increasing availability of other forms of distance communication, such as video conferencing (Choo et al. 2007). Moreover, BT expands the market potential of firms, creating new opportunities for acquiring contracts (Blum et al. 1997, Jones 2007), improves global corporate productivity, facilitates the creation of new jobs, and attracts new clients. Further, BT increases profits, sales, partnerships and innovation (Beaverstock et al. 2009, Machikita, Ueki 2010, WTTC 2011, Gustafson 2012). Two recent econometric studies provide evidence on the impacts of business travel. Poole (2010) demonstrates that business travel has a positive impact on the extensive export margin, thereby helping to overcome informational asymmetries in international trade. Concerning innovation,

\footnotetext{
${ }^{1}$ Note that the survey described in the fourth paragraph was implemented in 2014.
} 
Hovhannisyan, Keller (2015) show that BT has a significant effect beyond technology transfer, and in particular, leads to an increase in patenting. The literature thus provides ample evidence of business travel as an effective way of transferring knowledge, conserving long-term relationships, and coordinating and monitoring, all of which have a direct impact on trade and offshoring activities (HBR 2009, Cristea 2011).

Another strand of literature relates more closely to our topic, it concerns accessibility improvements caused by the introduction of high-speed train connections. In the economic literature, a lot has been written about the impact of high-speed trains (HST). For example, due to HST, isolated markets have been better integrated, monopolistic positions have been reduced and competition as well as productivity have increased (Blum et al. 1997). Moreover, there is an open debate on the impact of HST on GDP (Banister, Thurstain-Goodwin 2011) and on regional development (Vickerman et al. 1999, Gutiérrez 2001). The literature has also highlighted that this type of infrastructure will create new opportunities by offering additional locational advantages for economic activities and commuting/business trips, thus changing the traditional city roles (Ureña et al. 2009).

Looking at some European experiences, we can generally find an ex-post positive impact of high-speed trains on BT. In the Lille-Paris line, provided by the new TGV, business travel has increased by $1 / 3$ in both directions (Vickerman, Ulied 2009). This is also true for the Lyon-Paris line, where there is a growth in face-to-face contact in both directions, principally due to the activities between the subsidiary offices and the headquarters (Harman 2006). In general, many intermediate cities that are between two or more metropolitan areas -for example Lille, Cordoba, Zaragoza and Lyon- have numerous advantages from the building of new high-speed infrastructures. Thus, these intermediate cities experience a flourishing of their service sector (Ureña et al. 2009). Moreover, HST positively influences the city's position in the European urban hierarchy, empowering both dominant cities, i.e. those with the highest rank-order, and intermediate cities (McCann 2001, Mazzeo 2012). This urban structure replicates the Swiss situation well: due to high-speed trains, Lugano, a small intermediate city, will be closer to Zurich, a dominant economic pole.

The impacts of transport improvements on business travel on a micro level, which are the focus of this paper, have found less attention in research. According to Gutiérrez (2001), HST improves accessibility to cities by shortening travel time, and in particular, according to the definition of inbound/outbound accessibility (Törnqvist 1984), increases the face-to-face contact opportunities during a one-day trip, especially business-to-business trips (Blum et al. 1997, Willingers et al. 2007). The relevant literature underlines that accessibility is fundamental both for the decisions that a company takes and for the company's performance. In this sense, high-speed trains not only create possibilities for more face-to-face contacts with other enterprises, but also with customers, suppliers, partners and their workforce (Blum et al. 1997, Bruinsma, Rietveld 1998). The majority of such studies so far have been qualitative analyses, with no econometric measurements of the relationship between the increase in business travel and HST and have ambiguous results (Blum et al. 1997, Kobayashi, Okumura 1997, Harman 2006, Willingers et al. 2007). This is likely due to the scarce availability of micro data directly collected from firms.

Literature on the evaluation of travel time savings for business travellers can contribute to the arguments in this paper. Wardman et al. (2013), in a report commissioned by the UK Department for Transport, provide a comprehensive overview on methods and empirical evidence for the evaluation of travel time savings of business travellers. For Switzerland, Axhausen et al. (2006) estimate distance and income dependent values of travel time savings for various trip purposes and find a value of $30 \mathrm{CHF} /$ hour for business travel. We will draw partly on this literature in our theoretical considerations below.

Concerning the rationale for increasing business travel as a reaction to a reduced travel time, we will draw on the following works: Maggi 1989; Button et al. 1993; Button and Maggi 1995. These papers treat the issue from the perspective of choice between traveling for a face-to-face meeting and telecommunication contacts. The basic rationale is on the one hand, the superiority of face-to-face communication in terms of the quality of interaction, and on the other hand, the added transport cost. 
Hugoson (2001) also argued that the choice of face-to-face business contacts is associated with non-standardised information exchange and high transaction costs. These costs affect a firm's profit and differ between forms of interaction (i.e. telecommunication vs face-to-face contacts). The face-to-face meeting is chosen if the expected added profit from meeting is greater than the expected profit of a mediated contact and greater than the expected profit of no contact at all.

Apart from travel time, our theoretical framework (discussed in the next paragraph) does not provide indications for the specification of our empirical model. We therefore rely on empirical literature, which will now be reviewed.

As previous studies suggest, the variables influencing business travel behaviour can be grouped into characteristics of firms and current business relations.

Above all, the firm's sector influences the perception of the importance of accessibility. In particular, the empirical evidence shows that in the tertiary sector, e.g. business services and R\&D, face-to-face contacts are essential for the success of the activities (Blum et al. 1997, Jones 2007, Aguilera 2008). For this reason, the business services sector is the one that could benefit more from HST (Harman 2006). While a firm's size is a determinant for the perception of accessibility, we have not found any evidence supporting the hypothesis that the age of a firm significantly influences travel behaviour.

Another important determinant is the firm's spatial organisational structure, in terms of subsidiaries, branches and headquarters. In this context, business travel is essential to tying together spatially distributed subsidiaries (Aguilera 2008, Beaverstock et al. 2009).

Concerning current business relations, interactions with clients and suppliers are one of the main reasons for face-to-face contacts (Aguilera 2008, Beaverstock et al. 2009, Cristea 2011). According to a survey by the Harvard Business Review, more than $89 \%$ of review subscribers agree that face-to-face contacts are essential to "sealing a deal".

The destination of current business trips and the means of transport used can also influence the future behaviour (indeed, travel behaviour is based on habits; see Aarts et al. 1998, Aarts, Dijksterhuis 2000). We can imagine that firms, which nowadays have partners in a specific destination and visit them, will be the first to take advantage of new faster infrastructure.

\section{Theoretical framework and hypothesis}

As highlighted above, business travel is an essential ingredient of a company's activity in the context of globalisation, specialisation and spatial distribution of activities. Every firm interacts with its internal and external network of clients, suppliers etc. through a certain number of contacts. These contacts can take either the form of face-to-face meetings or any kind of telecommunication interaction. For simplicity, we assume the total number of business contacts to be fixed for a firm, and equal to $\bar{M}$. This is theoretically equivalent to a conditional demand for face-to-face meetings and telecommunication contacts, respectively. Therefore, following Maggi (1989), we model this decision as a cost-minimisation strategy regarding the number of direct vs telecommunication contacts. For the modelling of an unconditional demand for business meetings see Hugoson (2001). In our survey, it was not feasible to ask for the number of telecommunication contacts, and hence we observe only the current and future direct contacts. The future direct contacts might also include face-to-face contacts, which are stimulated by the new connection and thus increase the overall number of contacts. We will use the term "meetings" for contacts, where $M_{f f}$ are face-to-face meetings and $M_{t c}$ are telecommunication meetings. These meetings will in reality take many forms, concern various contents, and convey messages with different degrees of complexity, as their content can range from negotiations to simple internal briefings among departments.

We develop our argument defining the cost curves for face-to-face and telecommunication meetings, respectively. The differences in cost between the two modes regard on the one hand the presence of travel time $\left(T_{\text {travel }}\right)$ which is added to meeting time, and of monetary travel cost $\left(C_{\text {travel }}\right)$ only for face-to-face contacts. On the other hand is the cost dependence on complexity of content, only for telecommunication.

REGION: Volume 6, Number 3, 2019 


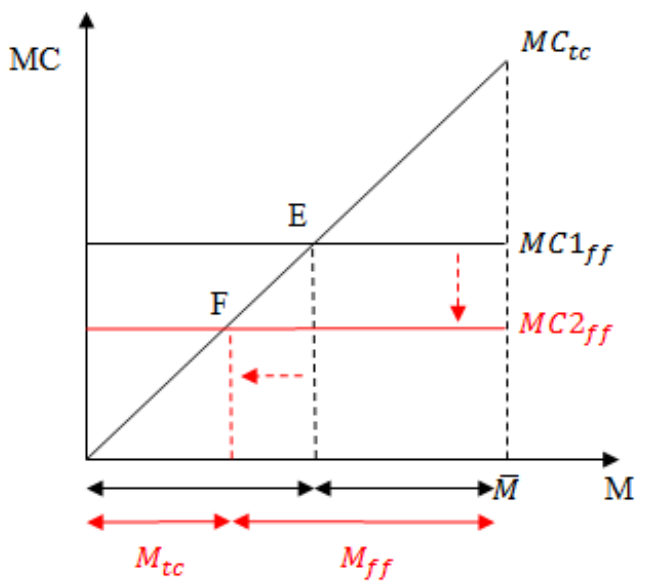

Figure 1: Marginal costs of face-to-face and telecommunication meetings

The two cost functions are:

$$
\begin{aligned}
C_{f f} & =V o T *\left(T_{\text {travel }}+T_{\text {meeting }}\right) * M+C_{\text {travel }} * M \\
C_{t c} & =V o T * T_{\text {meeting }} * f(M) \text { with } \quad f^{\prime}(M)>0 \text { and } f^{\prime \prime}(M)>0
\end{aligned}
$$

Where:

$$
\begin{aligned}
C_{f f} & \ldots \text { Cost for face-to-face meetings, } \\
C_{t c} & \ldots \text { Cost for telecommunication meetings, } \\
V o T & \ldots \text { Value of time, } \\
T_{\text {travel }} & \ldots \text { Travel time, } \\
T_{\text {meeting }} & \ldots \text { Meeting time, } \\
C_{\text {travel }} & \ldots \text { Monetary travel cost, } \\
M & \ldots \text { Number of meetings, } \\
f(M) & \ldots \text { function, which reflects the complexity of content in the meeting. }
\end{aligned}
$$

The intuition behind the formulation of the cost function for telecommunication is simply that the marginal cost of transmitting increasingly complex contents over a telecommunication mode is increasing. Standardising for simplicity meeting time to one $\left(T_{\text {meeting }}=1\right)$ and excluding corner solutions, cost-minimisation implies that the marginal costs of the two types of meetings are equal $M C_{f f}=M C_{t c}$ where:

$$
\begin{aligned}
M C_{f f} & =V o T *\left(T_{\text {travel }}+1\right)+C_{\text {travel }} \\
M C_{t c} & =V o T * f^{\prime}(M)
\end{aligned}
$$

Just as an example, if $f(M)=M^{2}$, the marginal cost for telecommunication meetings is linear, as illustrated in Figure 1. In this figure, the meetings are ordered by increasing complexity from left to right on the horizontal axis, and marginal costs on the vertical axis. The total number of meetings $\bar{M}$ is distributed between a certain number of face-to-face meetings and telecommunication interactions. When a decrease in travel time occurs, the line of the marginal cost for face-to-face contacts moves down (Figure 1 in red) and provokes a substitution of some of the telecommunication meetings of a certain complexity with face-to-face meetings. This substitution effect is realistic, given the experience that face-to-face contacts are the norm for very small local distances and in-house meetings. 
Note, we do not consider a variation in the monetary travel cost. While in general it can be assumed that prices might increase if the stakeholders of an infrastructure project want to recover their investment, this is not the case of the entirely publicly funded AlpTransit project. In Switzerland, the ticket prices of public transports are only distance dependent and, in order to improve accessibility, the standard policy is to invest in a new infrastructure, without adjusting prices.

Overall, according to these theoretical considerations, we expect that AlpTransit will have a positive impact on business trips, since it will reduce travel times.

\section{The survey}

The data was collected with an online survey among a sample of firms located in Ticino in 2014. The questionnaire was explicitly addressed to the CEO/upper management of the firm.

In order to build the sample, we used the Bureau van Dijk business listing, which reported some characteristics of the firms, such as sector, size, financial data, etc. Among them, sector is the only characteristic reported for all firms, while the other characteristics often are absent or not updated. Therefore, we stratified our sample based on sector. In 2014, the overall number of firms located in Ticino was divided as follows: $8.4 \%$ in primary sector, $14.4 \%$ in secondary sector, and $77.3 \%$ in tertiary sector. If we exclude the primary sector $^{2}$, the percentages increase to $16 \%$ for the secondary sector, and to $84 \%$ for the tertiary sector. We take these values as references in the sampling strategy. Therefore, a sample of 5890 firms was randomly selected from the Bureau van Dijk business listing, reflecting the sectoral composition described above.

The overall response rate was $13 \%$, in line with previous studies using questionnaires with firms: Kawamura (2004) obtained a response rate of $12.1 \%$ in a study on perceived accessibility and location choice of firms in the Chicago region (USA). Targa et al. (2006) obtained a response rate of only $6 \%$ in a survey on firms' relocation decisions in the state of Maryland (USA).

Obtaining high response rates in surveys with firms is complex, since the completion of the questionnaire requires that the survey is addressed to the right person within the firm, and that the CEO / upper management find time to complete it. Takin this into consideration, our response rate seems reasonable.

The response rate is slightly different between the two strata: $18 \%$ for the secondary sector and $12 \%$ for the tertiary sector. Looking at the differences between respondents and non-respondents, we found that $24.6 \%$ of non-respondents are in the secondary sector (versus $27.6 \%$ of respondents) and $75.4 \%$ of non-respondents belong to the tertiary sector (versus $72.4 \%$ of respondents).

From the 773 questionnaires filled in, we exclude incomplete questionnaires and all firms with zero employees (which are mainly foreign branches with only legal residence in Ticino), since they are not relevant for the purposes of our analysis. Therefore, 696 firms are considered in the model.

The survey was built following the most recent examples in the literature and can be divided into four main sections. The first section aims to collect general information about the enterprise: sector, age, spatial organisation (head office and branches), size, as well as information on relevant geographic markets (where suppliers and customers are located). In the second section, firms are asked to rate the importance and presence in Ticino of some location factors, such as accessibility, cost of labour, business taxes, etc.

The third part is devoted to business relations, in particular to understanding frequency, destination and means of transport used for business trips, with a focus on trips to Zurich. In the questionnaire, we specify that business visits are work-related travels to an irregular place of work. Finally, the last section contains some hypothetical questions on future actions of companies and in particular possible relocation outside Ticino and changes in BT due to AlpTransit.

Considering the possibility of easily reaching the train station, the geographical distribution of firms is important. The majority of respondents are concentrated in the

\footnotetext{
${ }^{2}$ Given the subject of our analysis (business travel), this omission is plausible.
} 
Table 1: Descriptive statistics of respondents

\begin{tabular}{llcc}
\hline Category & & Number & $\%$ \\
\hline Sector & Secondary & 192 & 27.6 \\
& Tertiary & 504 & 72.4 \\
Age & Less than 3 years old & 180 & 25.9 \\
& More than 4 years old & 516 & 74.1 \\
Organizational structure & Sole proprietorship & 546 & 78.4 \\
& Branch & 80 & 11.5 \\
& Headquarter & 70 & 10.1 \\
Size & Micro & 495 & 71.1 \\
& Small & 161 & 23.1 \\
& Medium-Large & 40 & 5.8 \\
\hline
\end{tabular}

city of Lugano, which is the main economic pole of Ticino and is the financial centre of the canton. The cities of Mendrisio and Chiasso (both in the south) follow in terms of highly populated areas. This concentration in the southern part of the canton, near Lugano where AlpTransit will stop, confirms that our respondents set is appropriate for the analysis.

Table 1 shows some descriptive statistics regarding the respondents to the questionnaire: $72.4 \%$ of firms operate in the tertiary sector; they are mainly firms, which are more than four years old (74.1\%) and sole proprietorship (78.4\%). Moreover, about $71 \%$ of respondents are micro firms (with less than 10 workers). The sample respondents' characteristics, which seem quite unbalanced, actually reflect the economic structure of Ticino, which is mainly composed of micro firms ( $86 \%$ of the businesses in Ticino in 2014) and firms operating in services $(77.3 \%)$.

\section{The empirical model}

As stated above, the last part of the survey contains some hypothetical questions, formulated as Likert scales, on a firms' future behaviour and in particular on possible changes in business travel due to AlpTransit. At the time of the inquiry in 2014, the new connection had been under construction for 15 years and still had 2 more years until completion, i.e. start of train operations. All train schedules, in terms of travel times, frequencies and train stops had already been defined by the Swiss Federal Railways. Therefore, we have no concerns regarding possible strategical answering by respondents.

We use the question, "How likely is it that the following employee categories (CEO, sales personnel, administrative staff and specialists) will travel more to Zurich, due to AlpTransit? 1 (Not at all likely), 5 (Very likely or almost certain)" as an indicator for the dependent variable in the ordered logit models.

The distribution of the propensity to increase BT to Zurich across the employee categories is shown in Table 2. Almost $14 \%$ of the respondents claim that their CEOs will travel more to Zurich due to AlpTransit (including both "likely" and "almost certain" categories). This percentage decreases for the other employee categories: respectively to $4.7 \%$ for administrative staff, to $10.4 \%$ for sales personnel and to $7.1 \%$ for specialists. Using these descriptive statistics, we have preliminary evidence that the considered employee categories have a different propensity to increase their travel due to AlpTransit.

Ordered logit models are used when the dependent variable is ranked on a scale. In particular, they are applied in stated preference choice experiments with Likert scales (Greene, Hensher 2009, Hess, Daly 2014).

Ordered logit models allow an analysis of hypothetical situations. Using self-assessed evaluations, we could try to capture agent's behaviour in a future situation. Many applied works, on various topics, can be found in the literature, for example: education (Machin, 
Table 2: Frequency of the propensity to increase BT to Zurich due to AlpTransit (\%)

\begin{tabular}{lccccc}
\hline & & & $\begin{array}{c}3- \\
\text { Neither } \\
\text { all likely }\end{array}$ & $\begin{array}{c}2- \\
\text { Unlikely } \\
\text { unlikely } \\
\text { nor likely }\end{array}$ & $\begin{array}{c}\text { Likely } \\
\text { likely or } \\
\text { almost } \\
\text { certain }\end{array}$ \\
\hline Increase BT of CEO & 61.4 & 12.5 & 12.2 & 6.2 & 7.8 \\
Increase BT of administrative staff & 79.5 & 9.8 & 6.0 & 2.4 & 2.3 \\
Increase BT of sales personnel & 71.1 & 9.9 & 8.6 & 6.5 & 3.9 \\
Increase BT of others (specialists) & 75.0 & 10.5 & 7.5 & 4.2 & 2.9 \\
\hline
\end{tabular}

Vignoles 2005), health status (Riphahn et al. 2003), transportation (Hensher et al. 2010) and mobilisation time during a hurricane (Sadri et al. 2013). To the best of our knowledge, this work is the first attempt to apply this type of model to a potential increase in business travel due to a high-speed train project.

Following the work presented in Greene, Hensher (2009), we consider a latent variable $y^{*}$ that captures how AlpTransit will modify firms' business relationships. This phenomenon can be described by the following latent regression model:

$$
y_{i}^{*}=\beta^{\prime} x_{i}+\epsilon_{i}
$$

and is observed in discrete form through a censoring mechanism. In particular, our latent variable is represented by a discrete and ordinal indicator $y_{i}$ :

$$
y_{i}=j \quad \text { if } \quad \mu_{j-1}<y_{i}^{*}<\mu_{j} \quad \text { for } j=1, \ldots, 5
$$

$y_{i}$ is the self-assessed likelihood on a 5 point Likert scale of increasing BT for each employee category due to AlpTransit.

The sample observations (firms) are labelled $i=1, \ldots, n$; the vector $x_{i}$ contains all our explanatory variables, which are assumed to be strictly exogenous of $\epsilon_{i}$ and are described in Table 3. The vector of unknown parameters $\beta$ and the thresholds $\mu_{j}$ (with $j=1, \ldots, 5$ ) are the object of estimation and inference.

Following the literature, we include among the regressors the number (measured on a Likert scale from 1 to 5 ) and location of suppliers and customers ${ }^{3}$, firms' characteristics: age, size, sector (in particular, manufacturing, business services, other activities in secondary and in tertiary sectors) and spatial organisation of the firm (if the firm is a branch, sole proprietorship or headquarters). In addition, we introduce frequency and destination (Milan, Ticino and Zurich) of current business travel as explanatory variables ${ }^{4}$. Some characteristics of current BT are taken into account such as the overnight stay in Zurich (due to the reduced travel time, firms could substitute them with more one-day trips) and the current use of train or car to go to the north of the Alps. $74 \%$ of respondents declared currently using car more than $50 \%$ of the times to go to Zurich, while $33 \%$ of companies answered using the train more than half of times. Only 1\% of firms indicated flight as means of transport to go to Zurich, but only occasionally. Finally, we include a variable indicating the distance in kilometres from the nearest AlpTransit station in Ticino (Lugano or Bellinzona) to take into account another element of access to HST.

We assume that the error term $\epsilon_{i}$ is IID Logistic distributed with mean 0 , scale parameter 1 and cumulative distribution function $\Lambda\left(\epsilon_{i} \mid x_{i}\right)=\Lambda\left(\epsilon_{i}\right)$.

\footnotetext{
${ }^{3}$ We do not introduce in the estimated models the variables "Suppliers in Ticino", "Suppliers in Italy", "Suppliers and customers in Western Europe", since only very few firms answered to these questions, resulting in coefficients that are not statistically significant.

${ }^{4}$ The variable "CEO current BT to Milan" is not introduced in the estimated model, since it is highly correlated with the variable "Sales personnel current BT to Milan".
} 
Table 3: Explanatory variables

\begin{tabular}{|c|c|c|c|}
\hline Variables & Operationalization & Mean & Std. Dev. \\
\hline Suppliers in Ticino & How many suppliers firm has in Ticino & 1.47 & 1.05 \\
\hline Suppliers in Italy & How many suppliers firm has in Italy & 1.33 & 0.79 \\
\hline Suppliers in Zurich & How many suppliers firm has in Zurich & 1.208 & 0.60 \\
\hline Suppliers in East Europe & How many suppliers firm has in East Europe & 1.057 & 0.34 \\
\hline Suppliers in Western Europe & How many suppliers firm has in W. Europe & 1.23 & 0.66 \\
\hline Clients in Ticino & How many clients firm has in Ticino & 3.63 & 1.35 \\
\hline Clients in Zurich & How many clients firm has in Zurich & 1.64 & 0.94 \\
\hline Clients in Italy & How many clients firm has in Italy & 1.82 & 1.01 \\
\hline Clients in East Europe & How many clients firm has in East Europe & 1.27 & 0.62 \\
\hline Clients in Western Europe & How many clients firm has in W. Europe & 1.59 & 0.95 \\
\hline Services & $\begin{array}{l}\text { Firm belongs to business services (financial and insu- } \\
\text { rance activities, real estate, administrative, scientific } \\
\text { and professional activities) - DV }\end{array}$ & 0.258 & 0.44 \\
\hline Manufacturing & Firm belongs to manufacturing sector - DV & 0.124 & 0.33 \\
\hline Other tertiary & $\begin{array}{l}\text { Firm belongs to tertiary sector, business services ex- } \\
\text { cluded - DV }\end{array}$ & 0.464 & 0.50 \\
\hline Other secondary & $\begin{array}{l}\text { Firm belongs to secondary sector, manufacturing ex- } \\
\text { cluded - DV }\end{array}$ & 0.153 & 0.36 \\
\hline Size & How many workers the plant in Ticino has & 16.37 & 55.37 \\
\hline Age & How old the firm is & 21 & 26.54 \\
\hline Sole proprietorship & Firm is a sole proprietorship - DV & 0.78 & 0.41 \\
\hline Branch & Firm is a branch of a company group - DV & 0.12 & 0.32 \\
\hline Headquarters & Firm is a headquarters of a company group - DV & 0.10 & 0.30 \\
\hline Other plant in Zurich & Firm has another plant in Zurich - DV & 0.048 & 0.22 \\
\hline CEO current BT to Ticino & Current BT frequency of CEO in Ticino & 4.23 & 1.82 \\
\hline CEO current BT to Zurich & Current BT frequency of CEO to Zurich & 2.06 & 1.19 \\
\hline CEO current BT to Milan & Current BT frequency of CEO to Milan & 2.13 & 1.39 \\
\hline Admin. current BT to Ticino & Current BT frequency of admin. staff in Ticino & 2.59 & 1.86 \\
\hline Admin. current BT to Zurich & Current BT frequency of admin. staff to Zurich & 1.32 & 0.74 \\
\hline Admin. current BT to Milan & Current BT frequency of admin. staff to Milan & 1.29 & 0.78 \\
\hline Comm. current BT to Ticino & Current BT frequency of sales personnel in Ticino & 3.16 & 2.03 \\
\hline Comm. current BT to Zurich & Current BT frequency of sales personnel to Zurich & 1.69 & 1.14 \\
\hline Comm. current BT to Milan & Current BT frequency of sales personnel to Milan & 1.71 & 1.25 \\
\hline Other current BT to Ticino & Current BT frequency of specialists in Ticino & 2.85 & 2.08 \\
\hline Other current BT to Zurich & Current BT frequency of specialists to Zurich & 1.45 & 0.91 \\
\hline Other current BT to Milan & Current BT frequency of specialists to Milan & 1.43 & 0.96 \\
\hline Current use of train to Zurich & Current use of train to go to Zurich (in percentage) & 0.14 & 0.29 \\
\hline Current use of car to Zurich & Current use of car to go to Zurich (in percentage) & 0.29 & 0.41 \\
\hline Overnight stay in Zurich & $\begin{array}{l}\text { Current overnight stay in Zurich after a business } \\
\text { meeting }\end{array}$ & 0.14 & 0.35 \\
\hline Distance & Distance in $\mathrm{km}$ from Alptransit station & 11.9 & 11.45 \\
\hline
\end{tabular}

Notes: DV ... dummy variable

Given these assumptions, the probabilities associated with the observed outcomes are:

$$
\begin{aligned}
\operatorname{Prob}\left[y_{i}=j \mid x_{i}\right] & =\operatorname{Prob}\left[\mu_{j-1}<y_{i}^{*}<\mu_{j}\right]=\operatorname{Prob}\left[\mu_{j-1}<\beta^{\prime} x_{i}+\epsilon_{i}<\mu_{j}\right] \\
& =\operatorname{Prob}\left[\epsilon_{i}<\mu_{j}-\beta^{\prime} x_{i}\right]-\operatorname{Prob}\left[\epsilon_{i}<\mu_{j-1}-\beta^{\prime} x_{i}\right] \\
& =\Lambda\left[\mu_{j}-\beta^{\prime} x_{i}\right]-\Lambda\left[\mu_{j-1}-\beta^{\prime} x_{i}\right]
\end{aligned}
$$

with $j=1, \ldots, 5$. For identification purposes, we impose that $\mu_{(j-1)}<\mu_{j} ; \mu_{0}=-\infty$ and $\mu_{5}=+\infty$.

The log-likelihood function, based on the previous implied probabilities, is:

$$
\log L=\sum_{i=1}^{n} \sum_{j=1}^{n} m_{i j} \log \left[\Lambda\left(\mu_{j}-\beta^{\prime} x_{i}\right)-\Lambda\left(\mu_{j-1}-\beta^{\prime} x_{i}\right)\right]
$$

where $m_{i j}=1$ if $y_{i}=j$ and 0 otherwise. Using the maximum likelihood estimator (MLE), it is possible to estimate the parameters $\beta$ and $\mu$. 
Table 4: Estimation results of the empirical models

\begin{tabular}{|c|c|c|c|c|}
\hline \multirow[t]{2}{*}{ Variables } & \multicolumn{4}{|c|}{ Ordered logit } \\
\hline & $\mathrm{CEO}$ & Admin. & Comm. & Others \\
\hline Suppliers in Zurich & $-0.203(0.18)$ & $-0.043(0.21)$ & $-0.202(0.19)$ & $-0.071(0.19)$ \\
\hline Suppliers in East Europe & $-0.44(0.33)$ & $-1.313^{* *}(0.57)$ & $-0.652^{*}(0.39)$ & $-0.62(0.39)$ \\
\hline Clients in Ticino & $0.117(0.08)$ & $0.07(0.10)$ & $0.054(0.09)$ & $0.063(0.09)$ \\
\hline Clients in Zurich & $0.28^{* * *}(0.1)$ & $0.207^{*}(0.11)$ & $0.325^{* * *}(0.11)$ & $0.151(0.11)$ \\
\hline Clients in Italy & $-0.254^{* *}(0.11)$ & $-0.093(0.13)$ & $-0.219^{*}(0.11)$ & $-0.107(0.12)$ \\
\hline Clients in East Europe & $0.031(0.14)$ & $0.321^{* *}(0.16)$ & $-0.003(0.16)$ & $0.06(0.17)$ \\
\hline Manufacturing & fixed & fixed & fixed & fixed \\
\hline Services & $1.123^{* * *}(0.35)$ & $0.726^{*}(0.44)$ & $0.732 * * \quad(0.38)$ & $0.843^{* *}(0.39)$ \\
\hline Other secondary & $1.08^{* * *}(0.35)$ & $1.081^{* *}(0.43)$ & $1.03^{* * *}(0.37)$ & $0.872 * *(0.38)$ \\
\hline Other tertiary & $0.463(0.33)$ & $0.297(0.41)$ & $0.543(0.35)$ & $0.346(0.38)$ \\
\hline Size & $-0.0006(0.0013)$ & $-0.002(0.001)$ & $-0.0023(0.002)$ & $-0.0006(0.0014)$ \\
\hline Age & $-0.0015(0.0033)$ & $-0.003(0.004)$ & $0.005(0.003)$ & $0.006^{*}(0.003)$ \\
\hline Headquarters & fixed & fixed & fixed & fixed \\
\hline Sole proprietorship & $-0.013(0.28)$ & $0.297(0.36)$ & $0.065(0.30)$ & $-0.078(0.32)$ \\
\hline Branch & $0.10(0.39)$ & $0.868^{*}(0.47)$ & $0.233(0.41)$ & $0.048(0.43)$ \\
\hline Other plant in Zurich & $-0.224(0.47)$ & $0.09(0.51)$ & $-0.22(0.47)$ & $-0.106(0.5)$ \\
\hline CEO current BT to Ticino & $0.173^{* * *}(0.06)$ & $-0.126^{*}(0.08)$ & $0.051(0.07)$ & $-0.0009(0.07)$ \\
\hline CEO current BT to Zurich & $0.37^{* * *}(0.11)$ & $0.33^{* * *}(0.13)$ & $0.094(0.12)$ & $0.138(0.13)$ \\
\hline Admin. current BT to Ticino & $-0.001(0.06)$ & $0.235^{* * *}(0.07)$ & $0.104(0.06)$ & $0.085(0.07)$ \\
\hline Admin. current BT to Zurich & $0.24^{*}(0.14)$ & $0.47^{* * *}(0.16)$ & $0.09(0.15)$ & $0.33^{* *}(0.16)$ \\
\hline Admin. current BT to Milan & $-0.27^{*}(0.14)$ & $-0.013(0.16)$ & $-0.398^{* *}(0.14)$ & $-0.573^{* * *}(0.16)$ \\
\hline Comm. current BT to Ticino & $0.03(0.06)$ & $0.052(0.08)$ & $0.114^{*}(0.07)$ & $-0.013(0.07)$ \\
\hline Comm. current BT to Zurich & $-0.045(0.11)$ & $-0.0012(0.14)$ & $0.211^{*}(0.13)$ & $-0.079(0.14)$ \\
\hline Comm. current BT to Milan & $-0.12(0.10)$ & $-0.14(0.13)$ & $0.391^{* * *}(0.11)$ & $0.101(0.12)$ \\
\hline Other current BT to Ticino & $-0.099^{*}(0.06)$ & $-0.048(0.07)$ & $-0.037(0.06)$ & $0.088(0.07)$ \\
\hline Other current BT to Zurich & $-0.085(0.13)$ & $0.045(0.15)$ & $0.071(0.13)$ & $0.268^{* *}(0.14)$ \\
\hline Other current BT to Milan & $0.345^{* * *}(0.12)$ & $0.092(0.14)$ & $0.206^{*}(0.12)$ & $0.479^{* * *}(0.13)$ \\
\hline Current use of car to Zurich & $0.51^{* *}(0.25)$ & $0.609^{* *}(0.31)$ & $0.349(0.27)$ & $0.085(0.29)$ \\
\hline Current use of train to Zurich & $1.67^{* * *}(0.31)$ & $0.967^{* * *}(0.36)$ & $1.13^{* * *}(0.32)$ & $1.019^{* * *}(0.34)$ \\
\hline Overnight stay in Zurich & $0.081(0.23)$ & $0.143(0.28)$ & $0.472^{*}(0.25)$ & $0.49 *(0.27)$ \\
\hline Distance $\mathrm{km}$ from & $0.003(0.007)$ & $0.004(0.009)$ & $0.007(0.008)$ & $0.003(0.008)$ \\
\hline Alptransit station & $0.003(0.007)$ & $0.004(0.009)$ & $0.007(0.008)$ & $0.003(0.008)$ \\
\hline Constant & - & - & - & - \\
\hline Observations & 696 & 696 & 696 & 696 \\
\hline Final Log-likelihood & -722.68 & -448.901 & -595.329 & -538.816 \\
\hline$R^{2} /$ Adjusted $\rho^{2}$ & 0.35 & 0.51 & 0.42 & 0.44 \\
\hline
\end{tabular}

Notes: Std. errors in parenthesis ${ }^{* * *} p<0.01,{ }^{* *} p<0.05,{ }^{*} p<0.1$

\section{Results and discussion}

Table 4 presents the results of the ordered logit models for the four employee categories. One of the main results of the analysis concerns the spatial structure of firms' current business travel. In particular, the greater a firm's BT within Ticino or a firm's BT to Zurich for one employee category currently are, the higher is the intention to travel more for the same category. We can call this "direct effect": AlpTransit will consolidate the travel behaviour of all these categories. It is interesting to notice that BT in Ticino and to Zurich have both positive and significant coefficients, if we look at the direct effects in all categories. This suggests that the two economies (Ticino and Zurich) are linked: not only will having current frequent business relationships with Zurich increase future travel, but also current trips within Ticino will boost such relationships.

We can also identify an "indirect effect", i.e. how current BT of one category influences the future BT of other categories. In particular, results show that the more frequently a CEO currently travels to Zurich, the higher the probability of more administrative staff also travelling. In addition, the more frequently administrative staff currently travel to Zurich, the higher the intention of increasing CEO and specialists' BT.

These "indirect effects" could be explained by the fact that different categories of employees travel for different purposes (Aguilera 2008): for example, after CEOs have 
Table 5: Direct and indirect effects. Marginal effects for $y=5$

\begin{tabular}{lcccc}
\hline Variables & CEO & Admin. & Comm. & Others \\
\hline CEO current BT to Zurich & $0.015^{* * *}$ & $0.0032^{* *}$ & 0.0017 & 0.002 \\
Admin. current BT to Zurich & $0.009^{*}$ & $0.0045^{* * *}$ & 0.0016 & $0.0049^{*}$ \\
Comm. current BT to Zurich & -0.002 & -0.00001 & $0.0037^{*}$ & -0.001 \\
Other current BT to Zurich & -0.004 & 0.00043 & 0.0007 & $0.0039^{*}$ \\
\hline
\end{tabular}

Notes: ${ }^{* * *} p<0.01,{ }^{* *} p<0.05,{ }^{*} p<0.10$

established a strategic contact or have signed a new contract, they may leave the concrete tasks to the operational arm (administrative staff), increasing BT of that category.

Table 5 presents the marginal effects for the highest value of the ordinal dependent variable $(y=5)$, highlighting the direct and indirect effects.

Concerning the importance of a specific sector, being a business service enterprise (financial and insurance activities, real estate, administrative, scientific and professional activities), i.e. activities which support companies, positively influences (if compared to manufacturing) the intention to travel more with AlpTransit for all categories. This is in line with the literature; in particular, the greatest impact of HST is likely if the service sector is already a key economic characteristic of the region (Harman 2006), as is the case for the service sector in Ticino.

Moreover, the variable "other activities in the secondary sector" (mainly construction) is significant for all the models and has a positive sign: construction activities show a higher propensity toward increasing travel with AlpTransit (according to our data some professional profiles, like plant designers and tile layers, travel a lot).

Looking at the variables which indicate the current transport mode chosen to go to Zurich, both use of train and use of car positively affect the probability of travelling more with AlpTransit in the future. For the variable "current use of car to Zurich", the coefficient is not statistically significant for the "sales personnel" and "specialists" model. Therefore, not only those using the train at present, but also CEOs and administrative staff who are using cars, will travel more to Zurich via high-speed train.

In order to interpret the magnitude of the estimated coefficients for their effect on the categories of the ordinal dependent variable (i.e. on the propensity to increase BT), the marginal effects need to be computed. Table 6 presents a selection of the marginal effects for the last two ordinal categories of the dependent variable for the four employee groups. In general, the marginal effects are larger for the CEO model than for the other models. In particular, the likelihood of increasing CEO business travel due to AlpTransit (considering $y=4$ and $y=5$ together), increases by $12 \%$ on average for firms belonging to business services, all else being equal; while for the other employee categories, the same percentage is $2 \%$ for administrative staff, $4.8 \%$ for sales personnel and $4 \%$ for specialists. Concerning the respondent's current transport habits, an increase of $1 \%$ in the current use of train by CEOs, is associated with a $14 \%$ growth in the likelihood of increasing CEO business travel due to AlpTransit. Instead, an increase of $1 \%$ in the current use of train for non-CEOs, is associated with a lower growth in the likelihood of using AlpTransit. Specifically, a $2 \%$ for administrative staff, $6.4 \%$ for sales personnel and $4 \%$ for specialists.

Other interesting results are found using variables related to the geographical distribution of clients and suppliers (Table 4). What is clearly observable is that a higher number of current clients in Zurich correlates to a higher intention to travel more to Zurich with AlpTransit (the coefficients are positive and significant for three out of four models). Therefore, AlpTransit will consolidate business relations between Ticino firms and Zurich (the major Swiss economic pole), as expected. Indeed, close communication between business partners, which often implies face-to-face contacts, turns out to be essential for successful business transactions (Cristea 2011). The results from the suppliers require caution in the interpretation, since only a limited number of firms answered to these questions.

Being a branch positively affects the probability to travel more because of AlpTransit if compared with the reference category (being the headquarters), but only for the 
Table 6: Marginal effects (selected results)

\begin{tabular}{lcccc}
\hline Variables & \multicolumn{2}{c}{ CEO } & \multicolumn{2}{c}{ Admin. } \\
& $\mathrm{y}=4$ & $\mathrm{y}=5$ & $\mathrm{y}=4$ & $\mathrm{y}=5$ \\
\hline Clients in Zurich & $0.011^{* * *}$ & $0.011^{* * *}$ & $0.0025^{*}$ & $0.002^{*}$ \\
Services & $0.056^{* * *}$ & $0.061^{* *}$ & $0.011^{*}$ & $0.0078^{*}$ \\
Other secondary & $0.057^{* * *}$ & $0.064^{* *}$ & $0.019^{*}$ & $0.016^{*}$ \\
Current use of car to Zurich & $0.021^{* *}$ & $0.021^{* *}$ & $0.0074^{*}$ & $0.0058^{*}$ \\
Current use of train to Zurich & $0.069^{* * *}$ & $0.069^{* * *}$ & $0.012^{* *}$ & $0.0093^{* *}$ \\
\hline
\end{tabular}

${ }^{* * *} p<0.01,{ }^{* *} p<0.05,{ }^{*} p<0.10$

\begin{tabular}{lcccc}
\hline Variables & \multicolumn{2}{c}{ Comm. } & \multicolumn{2}{c}{ Others } \\
& $\mathrm{y}=4$ & $\mathrm{y}=5$ & $\mathrm{y}=4$ & $\mathrm{y}=5$ \\
\hline Clients in Zurich & $0.013^{* * *}$ & $0.0057^{* * *}$ & 0.0038 & 0.0022 \\
Services & $0.033^{*}$ & $0.015^{*}$ & $0.026^{*}$ & $0.0156^{*}$ \\
Other secondary & $0.054^{* *}$ & $0.026^{*}$ & $0.029^{*}$ & $0.0178^{*}$ \\
Current use of car to Zurich & 0.013 & 0.006 & 0.0021 & 0.0012 \\
Current use of train to Zurich & $0.044^{* * *}$ & $0.02^{* * *}$ & $0.026^{* * *}$ & $0.0151^{* * *}$ \\
\hline
\end{tabular}

Notes: ${ }^{* * *} p<0.01,{ }^{* *} p<0.05,{ }^{*} p<0.10$

administrative staff model. This result could be explained by the purpose of travel, which is mainly internal training for branches.

The variable indicating the presence of other plants of the same company in Zurich is not significant, but this is probably due to the low number of firms with this characteristic among our respondents.

The overnight stay variable is statistically significant only for the last two columns in Table 4 and is positive: currently, after a meeting, employees stay overnight in Zurich, thus positively influencing the intention of increasing travel for sales personnel and specialists, if compared with those firms that currently do not remain overnight. We can imagine for sales personnel and specialists that are less "eminent" categories in a firm, there is a sort of substitution effect: they will no longer stay overnight in Zurich, which is quite expensive, but they will have one-day trips more frequently.

Finally, in order to support our hypothesis that professional status and hierarchical position influence business travel, we estimate a Pooled OLS model with cluster standard errors. Results are shown in Appendix A. The dummy variable for CEO is taken as a reference and the variables for the other three employee categories are introduced into the model. The estimated coefficients of administrative staff, sales personnel and others (specialists) are all statistically significant and negative, meaning that there is a difference between these categories and the CEO in the propensity to increase business travel after AlpTransit. Moreover, if we test the equivalence among these three coefficients, we can reject the null hypothesis that they are equal.

\section{Conclusions}

As demonstrated by the literature review, accessibility improvements have very complex but measurable implications on regional development. However, while these effects are empirically demonstrated on an aggregate level, implications of large infrastructure projects for individual firms have received little attention. In this research, we demonstrate that in the case of a clearly defined and predictable change in services of a new infrastructure project, it is possible to identify future adaptation of business travel to improved accessibility.

The main goal of this paper is to understand how the propensity of employees in various types of firms to travel between a small city and a dominant one will change after AlpTransit, the high-speed railway project in Switzerland. Using new micro data, we 
apply ordered logit models in order to investigate this issue. We obtain differentiated results among employees with different functions in various types of firms. Being a business services firm positively affects the probability of increasing face-to-face contacts. This result is in line with the literature: firms providing support to other companies take more advantage of high-speed trains (Blum et al. 1997, Jones 2007) and exploit the opportunities linked to an enlarged market (see the experience of Lyon companies: Harman 2006). Moreover, in this specific case, Ticino and Zurich have a common specialisation in financial, professional and scientific activities: both the localisation ratio and the specialisation ratio are quite high in both regions for those industries. We conclude that the existence of common clusters encourages the development of business relations between the two territories.

Another interesting finding from the study is that a firm's current level of business travel between Ticino and Zurich as well as intensive travel activity within Ticino, encourages future face-to-face contacts. We conclude that, in line with our theoretical considerations, BT habits influence future ones, reinforced by interaction effects among higher- and lower-level employee categories.

Overall, our results are in line with those in the ex-post evaluation literature. Therefore, we can conclude that our experiment is realistic and the ex-ante evaluation is credible. This might be due to the fact that the project considered, AlpTransit, intervenes in a context of existing strong business ties along the link, and that the future services provided in terms of time-table, frequency of service and prices were known in advance.

There are limits to the analysis of foreseen prospective impacts. Future research after the opening of AlpTransit will have to verify our findings for Ticino and include an equivalent approach to the analysis of the behaviour of firms in Zurich. After all, given the 'double importance' of accessibility, Ticino will also be closer for Zurich firms.

In conclusion, an ex-ante evaluation of the effects of new infrastructure is possible as long as the focus is on a specific travel category (in our case, business travel).

Overall, our study foresees positive impacts on future business travels due to HST, differentiating by functions of employees and current travel intensity. We therefore expect positive effects of the opening of the new connection on the Ticino economy.

\section{References}

Aarts H, Dijksterhuis A (2000) The automatic activation of goal-directed behaviour: The case of travel habit. Journal of Environmental Psychology 20: 75-82. CrossRef.

Aarts H, Verplanken B, van Knippenberg A (1998) Predicting behavior from actions in the past: Repeated decisions making or a matter of habit? Journal of Applied Social Psychology 28: 1355-1374. CrossRef.

Aguilera A (2008) Business travel and mobile workers. Transportation Research Part A 42: 1109-1116. CrossRef.

Axhausen KW, König A, Abay G, Bates JJ, Bierlaire M (2006) Swiss value of travel time savings. ETH Research Collection, Zürich

Banister D, Thurstain-Goodwin M (2011) Quantification of the non-transport benefits resulting from rail investment. Journal of Transport Geography 19[2]: 212-223. CrossRef.

Beaverstock JV, Derudder B, Faulconbridge JR, Witlox F (2009) International business travel: Some explorations. Geografiska Annaler Series B 91[3]: 193-202. CrossRef.

Blum U, Haynes KE, Karlsson C (1997) The regional and urban effects of high-speed trains. The Annals of Regional Science 31: 1-20. CrossRef.

Bruinsma F, Rietveld P (1998) The accessibility of cities in European infrastructure network. In: Bruinsma F, Rietveld $\mathrm{P}$ (eds), Is transport infrastructure effective? Springer, Heidelberg. CrossRef. 
Carbo JM, Graham DJ, Casas AD, Melo PC (2019) Evaluating the causal economic impacts of transport investments: Evidence from the Madrid-Barcelona high speed rail corridor. Journal of Applied Statistics 46[9]: 1714-1723. CrossRef.

Choo S, Lee TY, Mokhtarian PL (2007) Do transportation and communications tend to be substitutes, complements, or neither? U.S. consumer expenditures perspective, 1984-2002. Transportation Research Record 2010: 123-132

Cristea AD (2011) Buyer-seller relationships in international trade: Evidence from US states' exports and business-class travel. Journal of International Economics 84: 207-220. CrossRef.

De Bok M, Sanders F (2005) Firm relocation and accessibility of locations. Empirical results from the Netherlands. Journal of Transportation Research Board 1902: 35-43

Greene W, Hensher DA (2009) Modeling Ordered Choice. Cambridge University Press, Cambridge. CrossRef.

Gustafson P (2012) Managing business travel: Developments and dilemmas in corporate travel management. Tourism Management 33: 276-284. CrossRef.

Gutiérrez J (2001) Location, economic potential and daily accessibility: An analysis of the accessibility impact of the high-speed line Madrid-Barcelona-French border. Journal of Transport Geography 9: 229-242. CrossRef.

Harman R (2006) High-speed trains and the development and regeneration of cities. Greengauge21, London. http://www.greengauge21.net/wp-content/uploads/hsr-regnerationof-cities.pdf

HBR - Harvard Business Review Analytic Services (2009) Managing across distance in today's economic climate: The value of face-to-face communication. Harvard Business School Publishing, Harvard University

Hensher DA, Mulley C, Yahya N (2010) Passenger experience with quality-enhanced bus service: The tyne and wear superoute services. Transportation 37: 239-256. CrossRef.

Hess S, Daly A (2014) Handbook of choice modelling. Edward Elgar, Cheltenham. CrossRef.

Hovhannisyan N, Keller W (2015) International business travel: An engine of innovation? Journal of Economic Growth 20[1]: 75-104. CrossRef.

Hugoson P (2001) Interregional business travel and the economics of business interaction. Jönköping International Business School, Jönköping. http://hj.divaportal.org/smash/get/diva2:3898/FULLTEXT01.pdf

Jones A (2007) More than 'managing across borders?' the complex role of face-to-face interaction in globalizing law firms. Journal of Economic Geography 7[3]: 223-246. CrossRef.

Kawamura K (2004) Transportation needs, location choice and perceived accessibility for businesses. Journal of Transportation Research Board 1898: 202-210

Kobayashi K, Okumura M (1997) The growth of city systems with high-speed railway systems. The Annals of Regional Science 31: 39-56. CrossRef.

Leitham S, McQuaid RW, Nelson JD (2000) The influence of transport on industrial location choice: A stated preference experiment. Transportation Research Part A 34: 515-535. CrossRef.

Machikita T, Ueki Y (2010) The impacts of face-to-face and frequent interactions on innovation: Evidence from upstream-downstream relations. International Journal of Institutions and Economies 3[3]: 519-548 
Machin S, Vignoles A (2005) What's the good of education? The economics of education in the UK. Princeton University Press, Princeton

Maggi R (1989) Towards an economic theory of barriers to communication. Papers of the Regional Science Association 66: 131-141. CrossRef.

Marti M, Sommer H, Maggi R (2007) Erreichbarkeit und regionalwirtschaftliche entwicklung. Jahrbuch 2007 Schweizerische Verkehrswirtschaft. St. Gallen, 221-233

Mazzeo G (2012) Impact of high speed trains on the hierarchy of European cities. Jahrbuch für Regionalwissenschaft 32: 159-173. CrossRef.

McCann P (2001) Modern urban and regional economics. Oxford University Press, Oxford

Poole J (2010) Business travel as an input to international trade. Mimeo, University of California Santa Cruz

Riphahn R, Wambach A, Million A (2003) Incentive effects on the demand for health care: A bivariate panel count data estimation. Journal of Applied Economics 18[4]: 387-405. CrossRef.

Sadri AM, Ukkusuri SV, Murray-Tuite P (2013) A random parameter ordered probit model to understand the mobilization time during hurricane evacuation. Transportation Research Part C 32: 21-30. CrossRef.

Swarbrooke J, Horner S (2001) Business Travel and Tourism. Butterworth-Heinemann, Oxford. CrossRef.

Targa F, Clifton KJ, Mahmassani HS (2006) Influence of transportation access on individual firm location decisions. Journal of the Transportation Research Board 1977: 179-189. CrossRef.

Törnqvist G (1984) Contact potentials in the european system of cities. Contribution to Metropolitan Study, 16 CP-84-55

UNWTO - United Nations World Tourism Organization (2012) Tourism highlights. UNWTO publication, Madrid

Ureña JM, Menerault P, Garmendia M (2009) The high-speed rail challenge for big intermediate cities: A national, regional and local perspective. Cities 26: 266-279. CrossRef.

Vickerman R, Spiekermann K, Wegener M (1999) Accessibility in economic development in Europe. Regional Studies 33[1]: 1-15. CrossRef.

Vickerman R, Ulied A (2009) Indirect and wider economic impacts of high-speed rail. Economia y sociedad, Fundacion BBVA, Valencia

Wardman M, Batley R, Laird J, Mackie P, Fowkes T, Lyons G, Bates J, Eliasson J (2013) Valuation of travel time savings for business travellers. (report for the UK Department for Transport). Institute for Transport Studies, University of Leeds, Leeds. https://assets.publishing.service.gov.uk/government/uploads/system/uploads/attachment_data/file/251998/annexes-for-main-report-dft-005.pdf

Welch DE, Worm W (2005) International business travellers: a challenge for IHRM. In: Stahl GK, Björkman I (eds), Handbook of research in human resource management. Edward Elgar, Cheltenham, UK, 283-301. CrossRef.

Willingers J, Floor H, van Wee B (2007) Accessibility indicators for location choices of offices: An application to the intraregional distributive effects of high-speed rail in the Netherlands. Environment and Planning A 39: 2086-2098. CrossRef.

WTTC - World, Travel and Tourism Council (2011) Business travel: A catalyst for economic performance. London. https://www.deplacementspros.com/attachment/281391/ 
A Appendix: Estimation results of Pooled OLS model

\begin{tabular}{lr}
\hline Variables & Pooled OLS \\
\hline CEO & fixed \\
Administrative staff & $-0.481^{* * *}(0.03)$ \\
Sales personnel & $-0.244^{* * *}(0.033)$ \\
Others (specialists) & $-0.37^{* * *}(0.037)$ \\
Suppliers in Zurich & $-0.055(0.06)$ \\
Suppliers in East Europe & $-0.135^{* *}(0.06)$ \\
Clients in Ticino & $0.023(0.03)$ \\
Clients in Zurich & $0.094^{* *}(0.05)$ \\
Clients in Italy & $-0.071^{*}(0.04)$ \\
Clients in East Europe & $0.013(0.06)$ \\
Manufacturing & fixed \\
Services & $0.438^{* * *}(0.11)$ \\
Other secondary & $0.363^{* * *}(0.103)$ \\
Other tertiary & $0.245^{* * *}(0.097)$ \\
Size & $-0.0011^{* *}(0.0005)$ \\
Age & $0.0001(0.0012)$ \\
Headquarters & fixed \\
Sole proprietorship & $0.057(0.10)$ \\
Branch & $0.244^{*}(0.14)$ \\
Other plant in Zurich & $-0.113(0.19)$ \\
CEO current BT to Ticino & $0.032(0.02)$ \\
CEO current BT to Zurich & $0.085(0.06)$ \\
Admin. current BT to Ticino & $0.026(0.02)$ \\
Admin. current BT to Zurich & $0.141^{*}(0.08)$ \\
Admin. current BT to Milan & $-0.129^{* *}(0.05)$ \\
Comm. current BT to Ticino & $0.014(0.02)$ \\
Comm. current BT to Zurich & $0.047(0.05)$ \\
Comm. current BT to Milan & $0.054(0.03)$ \\
Other current BT to Ticino & $-0.015(0.02)$ \\
Other current BT to Zurich & $0.03(0.06)$ \\
Other current BT to Milan & $0.129^{* * *}(0.05)$ \\
Current use of car to Zurich & $0.08(0.11)$ \\
Current use of train to Zurich & $0.581^{* * *}(0.15)$ \\
Overnight stay in Zurich & $0.191(0.12)$ \\
Distance km from Alptransit station & $0.002(0.003)$ \\
Constant & $0.651^{* *}(0.26)$ \\
Observations & 2784 \\
R-squared & 0.22 \\
\hline &
\end{tabular}

Std. errors in parenthesis ${ }^{* * *} p<0.01,{ }^{* *} p<0.05,{ }^{*} p<0.1$

c) (7) (8) (c) 2019 by the authors. Licensee: REGION - The Journal of ERSA, European Regional Science Association, Louvain-la-Neuve, Belgium. This article is distributed under the terms and conditions of the Creative Commons Attribution, Non-Commercial (CC BY NC) license (http://creativecommons.org/licenses/by-nc/4.0/). 